\title{
The Effect of Single-Room Care Versus Open-Bay Care on the Incidence of Bacterial Nosocomial Infections in Pre-Term Neonates: A Retrospective Cohort Study
}

\author{
Sophie J. Jansen · Enrico Lopriore · Romy J. M. Berkhout • \\ Alieke van der Hoeven · Barbara Saccoccia · Jonne M. de Boer • \\ Karin E. Veldkamp · Martha T. van der Beek · Vincent Bekker
}

Received: October 8, 2020 / Accepted: November 28, 2020 / Published online: December 23, 2020

(C) The Author(s) 2020

\section{ABSTRACT}

Introduction: Nosocomial infections (NIs) are a major source of iatrogenic harm in neonatal intensive care units (NICUs). The influence of the infrastructure of NICUs on NIs is not well documented. This study aims to examine the effect of single-room units (SRU) versus openbay units (OBU) on the incidence of NIs, including central-line-associated bloodstream infections (CLABSI), in preterm neonates.

Methods: All preterm neonates $(<32$ weeks gestational age) admitted to our NICU were included. Two study periods were compared: one prior to (May 2015-May 2017) and one following (May 2017-May 2019) transition from OBU to SRU. Incidence density (number of infections per 1000 patient-days) and

Supplementary Information The online version contains supplementary material available at https:// doi.org/10.1007/s40121-020-00380-9.

S. J. Jansen $(\bowtie)$ - E. Lopriore · R. J. M. Berkhout . B. Saccoccia · J. M. de Boer - V. Bekker Division of Neonatology, Department of Pediatrics, Willem Alexander Children's Hospital-Leiden University Medical Center (LUMC), Leiden, The Netherlands

e-mail: s.j.jansen@lumc.nl

A. van der Hoeven · K. E. Veldkamp .

M. T. van der Beek

Department of Medical Microbiology, Leiden University Medical Center (LUMC), Leiden, The Netherlands cumulative incidence (number of infections per 100 neonates) for NIs were calculated. CLABSIs were calculated per 1000 central-line days. $U$ chart analysis was performed to determine special-cause variation in quarterly CLABSI and NI rates. Multivariate competing risk regression was performed to identify independent NI risk factors.

Results: Of the 712 included infants, 164 (23\%) infants acquired $\geq 1$ NIs. No differences were found in incidence density (13.68 vs. 12.62 , $p=0.62)$ or cumulative incidence of NI (23.97 vs. 22.02, $p=0.59$ ) between OBU and SRU. CLABSIs showed a similar non-significant reduction after the move (14.00 vs. 10.59, $p=0.51)$. $U$ chart analysis did not identify unit transition as a potential source of special-cause variation for CLABSI and NI. Competing risks regression analysis revealed longer duration of invasive mechanical ventilation as a significant risk factor for NI (subhazards ratio: 1.03 per day on ventilation, $p=0.01$ ).

Conclusion: Single-rooms are not associated with a significant reduction in NIs in the NICU. This study therefore does not add evidence that could support the transition to SRUs if based only on a large multimodal infection control strategy. Recommendations to build SRUs would require a wider justification, also taking into account other SRU benefits.

Keywords: Neonates; Nosocomial infections; Open-ward design; Single-room units 


\section{Key Summary Points}

\section{Why carry out this study?}

Nosocomial infections (NIs) continue to be a major source of iatrogenic harm in neonatal intensive care units (NICUs) worldwide.

A recommended strategy to interrupt the transmission of pathogenic organisms and prevent NIs is to hospitalise infants in single-patient rooms; however, evidence regarding the influence of the infrastructure of NICUs on NIs remains inconclusive.

This study aimed to examine the effect of single-room units (SRU) versus open-bay units (OBU) on the incidence of NIs, including central-line-associated bloodstream infections, and overall antibiotic use in preterm neonates.

\section{What was learned from the study?}

SRUs are not associated with significant reduction in NIs in the NICU.

This study therefore does not provide sufficient support for single-room care as an infection-control strategy. Further investigation regarding the influence of NICU room-privatisation on the burden of NIs is needed.

\section{DIGITAL FEATURES}

This article is published with digital features, including a summary slide, to facilitate understanding of the article. To view digital features for this article go to https://doi.org/10.6084/ m9.figshare.13293185.

\section{INTRODUCTION}

Even though advances in neonatal care have led to improved survival of premature infants, nosocomial infections (NIs), also known as hospital-acquired infections, continue to be a major problem in neonatal intensive care units (NICU) worldwide [1, 2]. Prospective surveillance data over 13 non-consecutive years from the Neonatal Research Network of the Eunice Kennedy Shriver National Institute of Child Health and Human Development (NICHD) demonstrated that $21-25 \%$ of very-low-birthweight (VLBW, $\leq 1500 \mathrm{~g}$ ) infants were found to have at least one episode of culture-confirmed sepsis, with the vast majority of infections being caused by Gram-positive organisms [1-4]. Central-line-associated bloodstream infections (CLABSIs) are the most common type of NI in neonates admitted to the NICU, and substantially factor into late-mortality, immediate- and long-term morbidity, length of hospital stay and health-care costs [5, 6]. Efforts in tackling neonatal NIs, including an ongoing assessment of associated morbidities, are required to eradicate this form of avertable iatrogenic harm.

A recommended strategy to interrupt the transmission of pathogenic organisms and prevent NIs is to hospitalise patients in single-patient rooms, facilitating better isolation from hospital-borne infectious agents and proper execution of standard infection-control measures [7, 8]. Unit design features that are believed to contribute to a potential reduction in hospital-acquired infections include the strategic placement of hand rub dispensers closer to the point of care (i.e. near the entrance door and adjacent to the incubator), reduced physical proximity between patients (functioning as an inherent form of isolation) and limited environmental contamination as a result of reduced traffic and medical equipment requiring routine cleaning $[8,9]$. However, evidence regarding the association between unit architectural design and prevention of NIs remains inconclusive. A retrospective cohort study investigating the association between NICU room configuration and colonisation by methicillin-resistant Staphylococcus aureus and 
development of late-onset sepsis found no effect on either, even after controlling for demographic, clinical and unit-based characteristics [9]. In contrast, a recent systematic review evaluating the difference between singleroom care versus open-bay care on a variety of neonatal outcomes in preterm infants did report a reduced incidence of sepsis in infants hospitalised in single rooms [10].

Following transition from an open-bay unit (OBU) to a newly constructed single-room unit (SRU) NICU at Leiden University Medical Center (LUMC) on May 15, 2017, we examined the effect of changing from an open, multiple-bed ward to an entirely single-room ward on the incidence of nosocomial infections, including CLABSI, and overall antibiotic use.

\section{METHODS}

\section{Setting and Study Design}

The LUMC is a tertiary university-affiliated hospital with a 25-bed level-III NICU constructed as a single-room facility with an average annual admission rate of approximately 500-600 in- and out-born neonates. The ward contains 16 single-patient rooms and four twinrooms (Supplementary Figure S1). In addition, a separate negative-pressure isolation room designed to prevent the spread of airborne pathogens is located adjacent to the main entrance of the ward. Each infant is hospitalised in a private room equipped with 1 hand-washing facility with touch taps and a dispenser with alcohol-based hand rub. Additional hand rub dispensers are available adjacent to each incubator. The average nurse-to-patient ratio is $1: 1$ for infants with high-dependency care, and 1:2 for infants requiring intermediate care. Prior to the transition to the new single-room facility, the NICU consisted of three open-bay rooms, two which served as intensive care (IC) units and one as a high-care (HC) unit. The two IC units were configured with, respectively, nine and seven beds, and the HC unit with nine beds. Bed occupancy rates depended on volatility in demand and staffing levels. Each unit was equipped with one sink
(Supplementary Figure S2). Hand rub dispensers were located next to each incubator and at the central nursing station. Depending on the level of care required, the standard nurse-to-patient ratio was 1:2 and 1:3 in the IC and HC units, respectively. The average area surrounding each incubator was approximately $2 \mathrm{~m}^{2}$.

We conducted a retrospective cohort study to evaluate the rate of nosocomial infections and antibiotic consumption in premature infants before and after transition to the new single-room NICU. Two study periods of 2 years each were compared: one prior to (May 15, 2015-May 14, 2017) and one following (May 16, 2017-May 15, 2019) unit transition. Approval and a waiver from the need to provide written informed consent were obtained from the institutional review board of LUMC (G19.070).

\section{Study Subjects and Data Collection Procedures}

Neonates born at $<32$ weeks gestational age and admitted to the NICU between May 15, 2015 and May 15, 2019 were included in this study. Infants born on the day of the unit transition (May 15, 2017) and those who were admitted to both unit types were excluded. Only data from first admissions were analysed.

For all study participants, the following data were extracted from electronic medical records for the period between admission and hospital discharge: birth date, gestational age, birth weight, sex, delivery mode (i.e. caesarian section or vaginal delivery), 5-min Apgar score, presence of major congenital anomalies, presence of surgical pathology, exposure to invasive mechanical ventilation, duration of invasive mechanical ventilation, exposure to a central-line, exposure to intravenous antibiotic therapy $\leq 24 \mathrm{~h}$ postpartum and $\geq 72 \mathrm{~h}$ after admission, total length of antibiotic treatment, prophylactic fluconazole use, length of hospital stay, in-hospital neonatal mortality and infection-related mortality (i.e. death attributed to infection as either the immediate or underlying cause). Information on NIs was obtained by reviewing patients' medical records, including laboratory 
(i.e. C-reactive protein), microbiology (i.e. organisms isolated from clinical cultures) and radiology (i.e. ultrasound, chest and abdominal radiography) results. Data pertaining to CLABSI included central-line type (i.e. umbilical venous, umbilical arterial or central-venous catheter), number of central-lines placed per infant, total duration of central-line use and isolated pathogenic microorganism(s) in case of a confirmed CLABSI.

\section{Sepsis Work-Up and Culture Collection}

Evaluation for sepsis was performed at the discretion of the attending physician in accordance with hospital protocol and included blood-culture analysis and at least one quantitative C-reactive protein (CRP) measurement $18 \mathrm{~h}$ after the initial sepsis work-up. Only culture results for specimens collected $\geq 72 \mathrm{~h}$ after NICU admission were considered. In case an infant was evaluated for sepsis more than once, all new unrelated episodes - i.e. absence of clinical signs or positive cultures between two episodes - were regarded as separate infection episodes.

\section{Definitions}

Nosocomial infection was defined as isolation of a pathogenic organism from a blood or other sterile fluid culture obtained $\geq 72 \mathrm{~h}$ after admission in combination with clinical symptoms of infection (temperature instability $\left(<36.5\right.$ or $\left.\geq 38^{\circ} \mathrm{C}\right)$, abdominal distension, feeding intolerance, respiratory distress, increase in ventilation requirements, apnea, hypotension, hyper-/hypoglycemia, metabolic acidosis, abnormal laboratory signs (i.e. leukocytosis, thrombocytopenia) or a CRP $\geq 10 \mathrm{mg}$ / L). CLABSI was defined as a laboratory-confirmed bloodstream infection occurring $\geq 72 \mathrm{~h}$ after birth and associated with an indwelling central-line and not related to an infection elsewhere. In addition, the definition requires that the central-line had been in place for $>2$ calendar days, up until the day of removal or the following day. Confirmed CLABSIs were subsequently categorised into one of three criteria based on the isolated pathogen (Supplementary Table S1). A positive culture with coagulase-negative staphylococci (CoNS) was considered an infection when a CRP $\geq 10 \mathrm{mg} / \mathrm{L}$ was measured within $36 \mathrm{~h}$ of infection onset. Cultures yielding other low virulence organisms (Corynebacterium spp., Micrococcus spp.) without elevated inflammatory markers were regarded as contamination and removed from further analyses. Given their contribution to short- and long-term neonatal morbidity, and in order to provide a comprehensive measure of the burden of NIs among preterm neonates, additional non-CLABSI NI types were also evaluated. As standardised definitions for NIs within the neonatal population are lacking, definitions for the non-CLABSI NI types were developed using well-established reference sources and adjusted according to specific neonatal symptomatology and diagnostic procedures. The diagnosis of a NEC was based exclusively on clinical parameters, as data on the prevalence of concurrent positive blood cultures in infants diagnosed with NEC are inconclusive [11]. Only grades IIA-IIIB according to Bell's staging criteria were collected [12]. Remaining definitions pertaining to each NI type are listed in Supplementary Tables S1 and S2.

\section{Statistical Analysis}

Data are reported as mean and standard deviation (SD), median and interquartile range (IQR) or absolute number and percentages, as appropriate. In univariate analysis, categorical data were analysed using the Chi-square test or Fisher's exact test, and continuous data using the independent $t$ test or Mann-Whitney $U$ test, as appropriate. Rates for NIs were calculated as the number of infection episodes per 1000 patient-days (incidence density) and number of infection episodes per 100 infants (cumulative incidence rate). CLABSI rates were calculated per 1000 central-line days. Considering infections as rare events, differences in infection rates in Poisson distribution were calculated using the exact conditional test. Shewhart $U$ charts were used to evaluate the presence of special-cause variation with regards to quarterly 
CLABSI and NI rates [13]. To evaluate change in antibiotic use between the two study periods, total days of treatment (DOT) per antibiotic agent and length of treatment (LOT) were calculated. If an infant received two or three different antibiotic agents within 1 day, each was counted as a separate DOT. Finally, to identify predictors for NI, univariate and multivariate Fine-Gray Competing Risk Regression models were created in which death without infection was modelled as a single competing outcome. Given that the outcome of death may modify the probability that an infection occurs, the competing risk modelling approach was chosen to allow for direct assessment of the association between a covariate and the cumulative incidence of infection. Unit type was included as the sole variable in the univariate model as the main outcome of interest. For the multivariate model, predictors were chosen based on clinical relevance. Retainment in or elimination from the model was based on maximum log-likelihood estimates using the stepwise selection approach. Subdistribution hazard (sDH) ratios comparing the probability of NI for each predictor value, conditional upon survival or occurrence of the competing risk (death), were computed along with corresponding 95\% confidence intervals (CI). All $p$ values were twotailed and $p<0.05$ was regarded as statistically significant. All statistical analyses were performed using R (v.3.6.2) [14].

\section{RESULTS}

\section{Demographic Characteristics}

Derivation of the study sample is shown in Fig. 1. Totals of 367 and 345 premature infants were admitted to the open-bay and single-room units, respectively, whose demographic characteristics are described in Table 1. There were significantly more infants in whom a centralline was inserted (61\% vs. $48 \%, p=0.005)$ during the open-bay period compared to after the conversion to single-room units. No other significant differences in neonatal characteristics between the two study periods were identified.

\section{Incidence of Nosocomial Infections}

A total of $200 \mathrm{NI}$ episodes occurred in 164 (23\%) infants (Table 2). No differences were found in the incidence density per 1000 patient-days (13.68 vs. $12.62 p=0.62$ ) nor cumulative incidence rate per 100 neonates (23.97 vs. 22.02, $p=0.59)$ between the historic open-ward and new single-room unit.

Apart from a slight increase in the number of primary blood stream infections and upper respiratory tract infections, an overall decrease was seen in the number of episodes for the remaining infection types after transition to the new unit, despite not being statistically significant (Table 3). No infant developed a meningitis during either study period.

During both study periods, three neonates died of a hospital-acquired infection, with mortality directly attributable to infection being $0.4 \%$ (Table 1 ). Of these three neonates, two were hospitalised in the new SRU. The cause of death of these three neonates were, respectively, E.coli sepsis-related multiorgan failure, methicillin-sensitive $S$. aureus-related respiratory and circulatory failure, and fulminant sepsis after NEC.

Figure 2 details the quarterly NI rates across the entire 4-year study period. The mean NI rate was 11.2 per 1000 patient-days. $U$ chart analysis did not reveal any occasion in which the variation in NI incidence was higher or lower than expected by random (common-cause) variation, particularly around the time of unit transition.

\section{Central-line Characteristics and Incidence of CLABSI}

As the most common type of NIs in neonates, we evaluated the effect of unit transition on the occurrence of CLABSI by assessing changes in central-line use, dwell-time and incidence of central-line infections among neonates with one or more central-lines (Table 4). Over the two study periods, 779 central-lines with 2963 central-line days were placed in 390 infants, with significantly more central-lines placed during the open-bay period compared to the single-room period (430 vs. $349, p=0.004$ ). No 


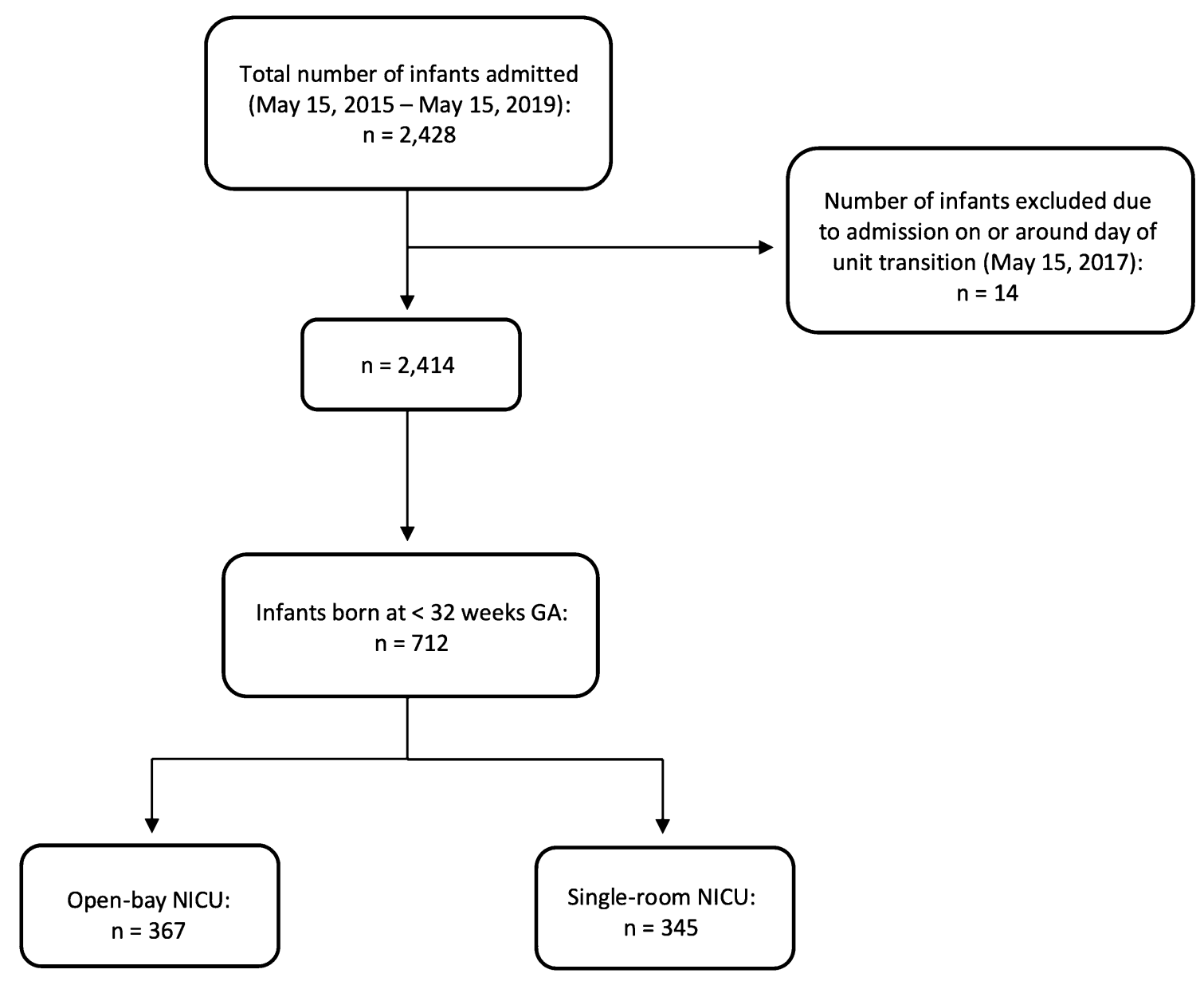

Fig. 1 Flow chart of study participant enrollment

difference was found in average number of central-line days per child, type of inserted central-line, and average age at central-line insertion and removal. Overall, 23 neonates developed at least one CLABSI in the OBU compared to 14 in the SRU, although this difference was not statistically significant $(p=0.51)$. The $25 \%$ reduction in CLABSI rate (14-10.59 per 1,000 central-line days) after unit transition was also not statistically significant $(p=0.51)$.

Figure 3 shows the quarterly CLABSI rates across the entire 4-year study period, with the mean CLABSI rate being 12.5 infections per 1000 line-days. No special-cause signalling, specifically around unit transition, was identified by $U$ chart analysis. A steep increase in the infection rate in the period May-July 2019 is present, likely resulting from a lower number of line-days (36.37 line-days) compared to prior quarters.

\section{Pathogen Distribution}

Supplementary Table S3 details the pathogen distribution of the most prevalent NI types, namely, CLABSI and primary bloodstream infection (PBSI). For both infection types, the majority of monomicrobial infections were caused by Gram-positive cocci (CLABSI: 92\%, PBSI: 84\%), with Gram-negative organisms accounting for 5.4 and $7 \%$ of CLABSI and PBSI episodes, respectively. There was a slight decrease in CLABSIs and PBSIs owing to CoNS after unit transition (CLABSI: $87 \%$ vs. $71 \%$, PBSI: $70 \%$ vs. $68 \%$ ). Other frequently isolated Gram-positive organisms included S. aureus and 
Table 1 Infant and maternal characteristics

\begin{tabular}{|c|c|c|c|}
\hline Characteristic & $\begin{array}{l}\text { OBU } \\
(n=367)\end{array}$ & $\begin{array}{l}\text { SRU (n } \\
=345)\end{array}$ & $P$ value \\
\hline Sex (female), $n(\%)$ & $171(47)$ & $175(46)$ & 0.30 \\
\hline $\begin{array}{l}\text { Birth weight }(\mathrm{g}), \\
\text { mean }(\mathrm{SD})\end{array}$ & $1285(377)$ & $1240(382)$ & 0.11 \\
\hline $\begin{array}{l}\text { Number of VLBW } \\
\text { infants, } n(\%)\end{array}$ & $260(71)$ & $253(73)$ & 0.51 \\
\hline $\begin{array}{l}\text { Number of ELBW } \\
\text { infants, } n(\%)\end{array}$ & $91(25)$ & $99(29)$ & 0.28 \\
\hline $\begin{array}{l}\text { Gestational age } \\
\text { (weeks), median } \\
\text { (IQR) }\end{array}$ & $29(4)$ & $29(4)$ & 0.84 \\
\hline $\begin{array}{c}\text { Delivery by caesarian } \\
\text { section, } n(\%)\end{array}$ & $196(53)$ & $185(54)$ & 1 \\
\hline $\begin{array}{l}\text { 5-min Apgar score, } \\
\text { median }(\mathrm{IQR})^{\mathrm{a}}\end{array}$ & $8(2)$ & $8(2)$ & 0.17 \\
\hline $\begin{array}{l}\text { Antenatal steroids, } \\
n(\%)^{\mathrm{b}}\end{array}$ & $340(93)$ & $321(93)$ & 0.95 \\
\hline $\begin{array}{l}\text { Postnatal steroids, } \\
n(\%)\end{array}$ & $19(5.2)$ & $20(5.8)$ & 0.84 \\
\hline $\begin{array}{l}\text { Exposure to central- } \\
\text { line, } n(\%)\end{array}$ & $223(61)$ & $167(48)$ & 0.005 \\
\hline $\begin{array}{l}\text { Major congenital } \\
\text { anomaly, } n(\%)^{\mathrm{c}}\end{array}$ & $10(2.7)$ & $3(0.9)$ & 0.12 \\
\hline $\begin{array}{l}\text { Exposure to invasive } \\
\text { mechanical } \\
\text { ventilation, } n(\%)^{\mathrm{d}}\end{array}$ & $140(38)$ & $129(37)$ & 0.89 \\
\hline $\begin{array}{l}\text { Total ventilation- } \\
\text { days, } n\end{array}$ & 996 & 956 & 0.97 \\
\hline $\begin{array}{l}\text { Duration of invasive } \\
\text { mechanical } \\
\text { ventilation per } \\
\text { infant (days), } \\
\text { median (IQR) }\end{array}$ & $4(7)$ & $5(6)$ & 0.97 \\
\hline $\begin{array}{l}\text { Surgical pathology, } \\
n(\%)\end{array}$ & $15(4.1)$ & $11(3.2)$ & 0.66 \\
\hline $\begin{array}{l}\text { Prophylactic } \\
\text { fluconazole use, } \\
n(\%)\end{array}$ & $57(16)$ & $62(18)$ & 0.44 \\
\hline
\end{tabular}

Table 1 continued

\begin{tabular}{lccc}
\hline Characteristic & $\begin{array}{l}\text { OBU } \\
(n=367)\end{array}$ & $\begin{array}{l}\text { SRU }(n \\
=345)\end{array}$ & $P$ value \\
\hline $\begin{array}{l}\text { Total patient-days, } n \\
\text { Length of hospital } \\
\text { stay per child } \\
\text { (days), median } \\
\quad \text { (IQR) }\end{array}$ & $13(25)$ & $13(23)$ & 0.36 \\
$\begin{array}{l}\text { In-hospital mortality, } \\
n(\%)\end{array}$ & $15(4.1)$ & $20(5.8)$ & 0.38 \\
$\begin{array}{l}\text { Infection-related } \\
\text { mortality, } n(\%)\end{array}$ & $1(0.3)$ & $2(0.6)$ & 0.96 \\
\hline
\end{tabular}

Significant $P$ value shown in bold

$O B U$ open-bay unit, $S R U$ single-room unit, $S D$ standard deviation, $g r$ grams, $V L W B$ very-low birth-weight, $E L B W$ extremely-low birth-weight, $I Q R$ interquartile range

${ }^{a}$ Results based on 365 and 342 infants in OBU and SRU, respectively (five missing variables)

b Results based on 361 and 341 infants in OBU and SRU, respectively (ten missing variables)

c Defined as a condition that leads to significant medical, social or cosmetic consequences and typically requires medical intervention such as oral facial clefts, cyanotic heart defects, neural tube defects and limb deficiencies

${ }^{d}$ Ventilation modalities include conventional mechanical ventilation with pressure support or high frequency oscillation (HFO)

e Results displayed for infants exposed to invasive mechanical ventilation only

Table 2 Rates of nosocomial infections

\begin{tabular}{lcll}
\hline & OBU & SRU & $\boldsymbol{P}$ value \\
\hline Total infection episodes, $n$ & 112 & 88 & - \\
$\begin{array}{l}\text { Incidence density per 1000 } \\
\quad 13.68\end{array}$ & 12.62 & 0.62 \\
$\quad \begin{array}{l}\text { patient-days } \\
\text { Infants with an infection, } n\end{array}$ & 88 & 76 & - \\
$\begin{array}{l}\text { Cumulative incidence per 100 } \\
\quad \text { infants }\end{array}$ & 23.97 & 22.02 & 0.59 \\
\hline
\end{tabular}


Table 3 Number of infection episodes per infection type

\begin{tabular}{llll}
\hline Infection type & \multicolumn{3}{l}{ Unit type } \\
\cline { 2 - 4 } & OBU & SRU & $\boldsymbol{P}$ value \\
\hline CLABSI & 23 & 14 & 0.24 \\
Persistent bacteremia after & 3 & 1 & 0.66 \\
$\quad$ CLABSI & & & \\
PBSI & 40 & 44 & 0.52 \\
SBSI & 5 & 3 & 0.79 \\
HAP & 2 & 0 & 0.51 \\
VAP & $3(3.01)$ & $2(2.09)$ & 1 \\
URTI & 1 & 4 & 0.33 \\
NEC & 25 & 17 & 0.36 \\
UTI & 3 & 2 & 1 \\
Skin and/or soft tissue & 3 & 1 & 0.66 \\
$\quad$ infection & & & \\
Conjunctivitis & 4 & 0 & 0.15 \\
Total & 112 & 88 &
\end{tabular}

CLABSI central-line associated bloodstream infection, $P B S I$ primary bloodstream infection, SBSI secondary bloodstream infection, HAP hospital-acquired pneumonia, $V A P$ ventilator-associated pneumonia, URTI upper respiratory tract infection, NEC necrotising enterocolitis, UTI urinary tract infection

${ }^{a}$ Results in parentheses represent incidence per 1000 ventilation-days

Enterococcus spp. (E. faecium), the former increasing in prevalence among PBSIs following transition to the SRU. Two PBSI episodes were found to be polymicrobial, both predominated by Gram-negative organisms. Only a small proportion of CLABSI and PBSI episodes were caused by Gram-negative organisms and fungi throughout the entire study period.

\section{Antibiotic Exposure}

No difference between the two units was found in number of neonates who received antibiotic treatment within the first $24 \mathrm{~h}$ postpartum $(62 \% \quad$ vs. $\quad 57 \%, \quad p=0.19) \quad$ (Supplementary Table S4). Likewise, no difference between the units was found in the proportion of neonates who were treated with one or more courses of antibiotics $\geq 72 \mathrm{~h}$ after admission $(64 \%$ vs. $57 \%, p=0.06)$. Total LOTs of 2832 and 2413 days were registered in the OBU and SRU, respectively, with the normalised difference not statistically significant (345 vs. 346 per 1000 patient-days, $p=0.51$ ). Similarly, no significant decrease was found in antibiotic consumption accounting for each agent (DOT, 616 vs. 607 per $1,000$ patient-days, $p=0.99)$.

\section{Multivariate Analysis by Fine-Gray Competing Risk Regression Model}

Supplementary Table S5 shows the subdistribution hazard ratios estimated from the Fine-Gray competing risk regression model. In univariate analysis, unit type was not associated with a change in risk of infection (sDH: 0.95, $p=0.78$ ). In multivariate analysis, 12 variables, namely unit type, gestational age, sex, 5-min Apgar score, birth weight, birth modus, antenatal steroids, duration of invasive mechanical ventilation, exposure to a central-line, central-line dwell-time, antibiotic treatment within $24 \mathrm{~h}$ after birth and length of hospital stay were selected to be evaluated as potential risk factors for NI. Only duration of invasive mechanical ventilation was identified as a minor risk factor (sDH: 1.03, $p=0.01$ ). No other variables, including single-room care, were significantly associated with $\mathrm{NI}$ in multivariate analysis.

\section{DISCUSSION}

We conducted a retrospective cohort study to assess the incidence of hospital-acquired infections in premature neonates admitted to a newly designed ward with single-rooms versus a historic ward with three multi-bed wings. Our findings revealed a non-significant overall reduction in NIs after unit transition. Similar non-significant reductions were found in the CLABSI rate and the number of other NI types after unit transition. Gram-positive organisms, in particular CoNS, were the most frequently isolated pathogens during both study periods. We found no significant reduction in the proportion of infants treated with antibiotics nor in 


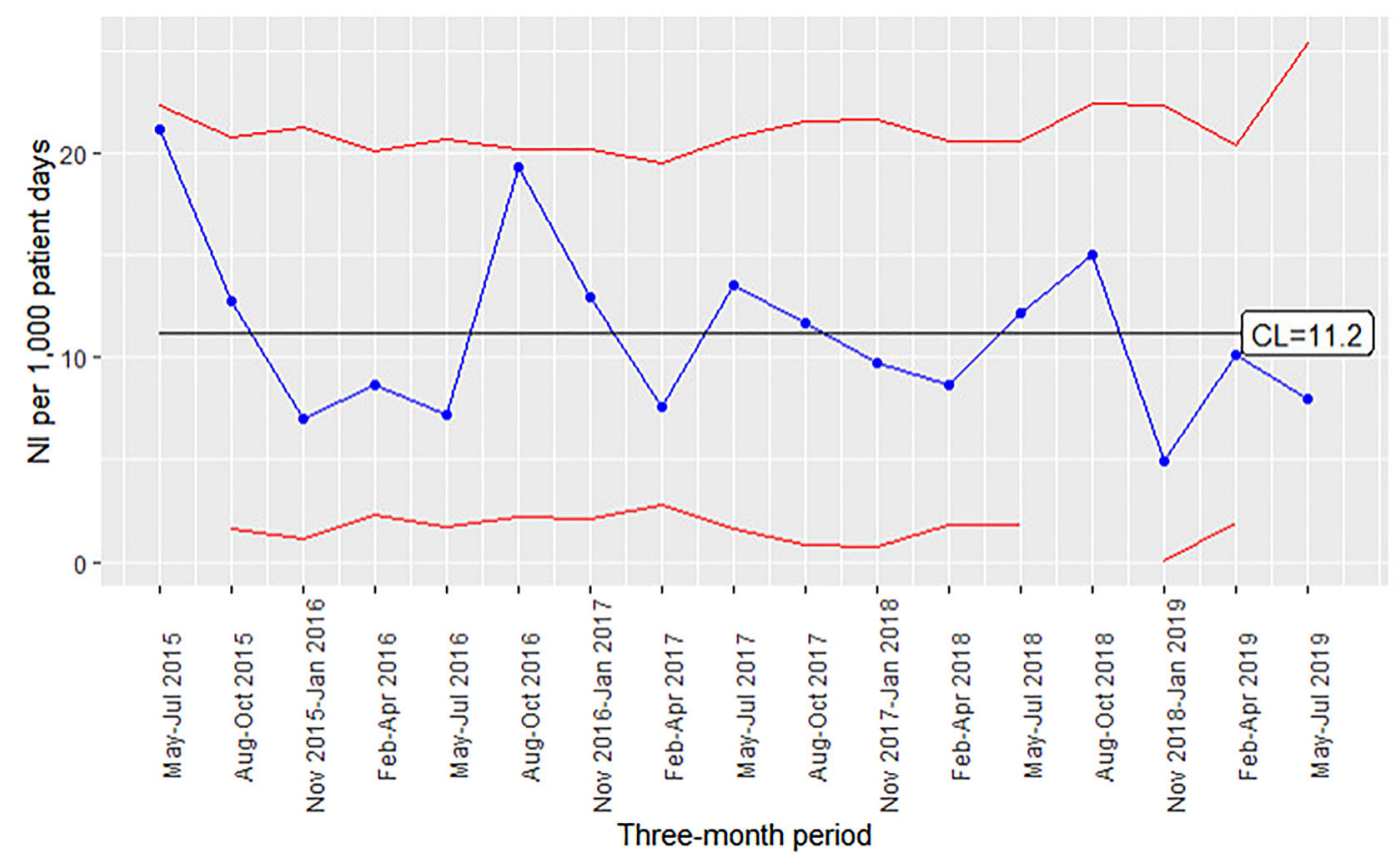

Fig. $2 U$ chart for overall NI rates by 3-month periods. The central line $(C L)$ represents the internal mean NI rate from May 15, 2015 to May 15, 2019. The upper and lower lines represent the upper and lower control limits, respectively (UCL, LCL). LCL approaches zero from

overall antibiotic consumption. Only duration of invasive mechanical ventilation, which was not different between the unit types, was identified as a risk factor for NI.

Even though the present study found a decrease in the number of infections, this decrease was statistically non-significant, and it also remains unclear if, and to what extent, the transition from OBU to SRU contributed to this decrease. While we aimed to identify unit transition as a potential source of special-cause variation in our $U$ charts, we found only random variation present, suggesting that no particular infection prevention element or change in clinical practice contributed to a statistically significant reduction in NI rates during the study period. Moreover, unwavering adherence to hand hygiene practices may have further diminished the impact of unit configuration. The overall decrease in the number of children with an infection and the number of infection episodes may also have been part of an existing
May 2018 to November 2018 and from February 2019 onwards and is therefore not depicted. Final quarter (May-Jul 2019) displayed as full 3-month period, although data present up until May 15, 2019

declining trend rather than a result of the new SRU design.

It is important to note that our NI rates are slightly higher compared to those reported in other studies [15-18], presumably because we chose to also report less severe (i.e. skin and eye) and secondary infections (i.e. persistent bacteremia after CLABSI, secondary bloodstream infection). Although not immediately lifethreatening, these infection types still act as an important reservoir of pathogenic organisms and may lead to clinically manifested consequences [19]. The substantial variability in definitions of neonatal CLABSI across studies in combination with different baseline populations render an adequate comparison of CLABSI rates difficult.

Unlike the number of CLABSIs, which did not decrease significantly after conversion to the SRU, the number of central-lines placed was significantly lower. At our institution, centrallines are most frequently inserted in infants born at $<28$ weeks' gestation and/or with a 
Table 4 Central-line characteristics in infants with a central-line

\begin{tabular}{|c|c|c|c|}
\hline Characteristic & OBU & SRU & $P$ value \\
\hline Central-lines placed, $n$ & 430 & 349 & 0.004 \\
\hline Total central-line days, $n$ & 1642.5 & 1321.1 & 0.24 \\
\hline $\begin{array}{l}\text { Central-line days per } \\
\text { infant, median (IQR) }\end{array}$ & $\begin{array}{l}6.71 \\
\quad(5.28)\end{array}$ & $\begin{array}{l}7.03 \\
(4.02)\end{array}$ & 0.24 \\
\hline $\begin{array}{l}\text { Number of VLBW infants } \\
\text { with a central-line, } n(\%)^{\mathrm{a}}\end{array}$ & $\begin{array}{l}188 \\
(72)\end{array}$ & $\begin{array}{l}155 \\
(61)\end{array}$ & 0.07 \\
\hline $\begin{array}{l}\text { Number of ELBW infants } \\
\text { with a central-line, } n(\%)^{\mathrm{a}}\end{array}$ & $87(96)$ & $89(90)$ & 0.88 \\
\hline \multicolumn{4}{|l|}{ Central-line type, $n(\%)$} \\
\hline UVC & $\begin{array}{l}173 \\
(40)\end{array}$ & $\begin{array}{l}135 \\
(39)\end{array}$ & 0.19 \\
\hline UAC & $\begin{array}{l}114 \\
(27)\end{array}$ & $80(23)$ & \\
\hline CVC & $\begin{array}{l}143 \\
(33)\end{array}$ & $\begin{array}{l}134 \\
(38)\end{array}$ & \\
\hline CLABSI episodes, $n^{\mathrm{b}}$ & 23 & 14 & 0.51 \\
\hline $\begin{array}{l}\text { Infants with } \geq 1 \\
\qquad \operatorname{CLABSI}(s), n^{c}\end{array}$ & 23 & 14 & 0.64 \\
\hline $\begin{array}{l}\text { Age at insertion }(\mathrm{d}), \\
\text { median }(\mathrm{IQR})\end{array}$ & $\begin{array}{l}0.85 \\
\quad(0.48)\end{array}$ & $\begin{array}{l}0.92 \\
\quad(0.69)\end{array}$ & 0.07 \\
\hline $\begin{array}{l}\text { Age at removal }(\mathrm{d}), \text { median } \\
\text { (IQR) }\end{array}$ & $\begin{array}{l}8.44 \\
\quad(5.68)\end{array}$ & $\begin{array}{l}8.93 \\
\quad(5.93)\end{array}$ & 0.13 \\
\hline $\begin{array}{l}\text { CLABSI incidence per } \\
1000 \text { central-line days }\end{array}$ & 14.00 & 10.59 & 0.51 \\
\hline
\end{tabular}

Significant $P$ value shown in bold

$I Q R$ interquartile range, VLBW very-low-birth-weight $(<1500 \mathrm{~g}), \quad E L B W \quad$ extremely-low-birth-weight $(<1000 \mathrm{~g})$, CLABSI central-line associated bloodstream infection, $U V C$ umbilical-venous catheter, $U A C$ umbilicalarterial catheter, $C V C$ central-venous catheter, $d$ days

a $V L B W$ total group consists of 260 and 253 infants in OBU and SRU, respectively, ELBW total group consists of 91 and 99 infants in OBU and SRU, respectively

b Calculated difference based on total number of centrallines placed $(n=779)$

c Calculated difference based on total number of infants with a central-line $(n=390)$ birth weight $<1000 \mathrm{~g}$. All insertion procedures are performed by experienced neonatologists, physician assistants or competent paediatric residents according to a standardised institution-specific protocol and checklist. Although no formal changes in the central-line insertion and maintenance policy were made during either study periods, the decrease in the number of central-lines placed is suggestive of a more restrictive policy regarding the use of invasive medical devices, which may eventually lead to a lower CLABSI rate. The absence of meningitis in either study period may in part be due to our stringent definition which does not presumptively rely only on abnormal CSF parameters (i.e. cell count, glucose, protein levels). Also, CoNS was the primary pathogen isolated from all CSF cultures collected from infants clinically suspected of a meningitis, suggesting specimen contamination instead of true infection.

Our non-significant reduction in NIs following unit transition contrasts with findings from a recent systematic review and metaanalysis assessing the effect of single-family rooms versus open-bay units on a variety of neonatal outcomes in preterm infants, including late-onset sepsis [10]. Nevertheless, only six studies assessing culture-proven late-onset sepsis were included, four of which had moderate risk of bias and thus a possible overestimation of the intervention effect. Additionally, compared to our study, three of the six studies included found a relatively larger reduction (5-9\%), suggestive of higher pre-unit transition rates resulting in larger reductions $[15,20]$. Moreover, the true effect of single-room care on lateonset infection rates may have been overestimated, as publication bias was not assessed. Recommendations to build SRUs would therefore require a wider justification also taking into account other SRU benefits.

A secondary objective of our study was to examine whether single-room care would lead to a decrease in overall antibiotic exposure, perhaps as a result of a concomitant decline in the number of NIs. We found no difference in the number of infants treated with antibiotics in the first $24 \mathrm{~h}$ after birth between SRU and OBU. This empiric treatment is often initiated due to a suspected early-onset infection, the 


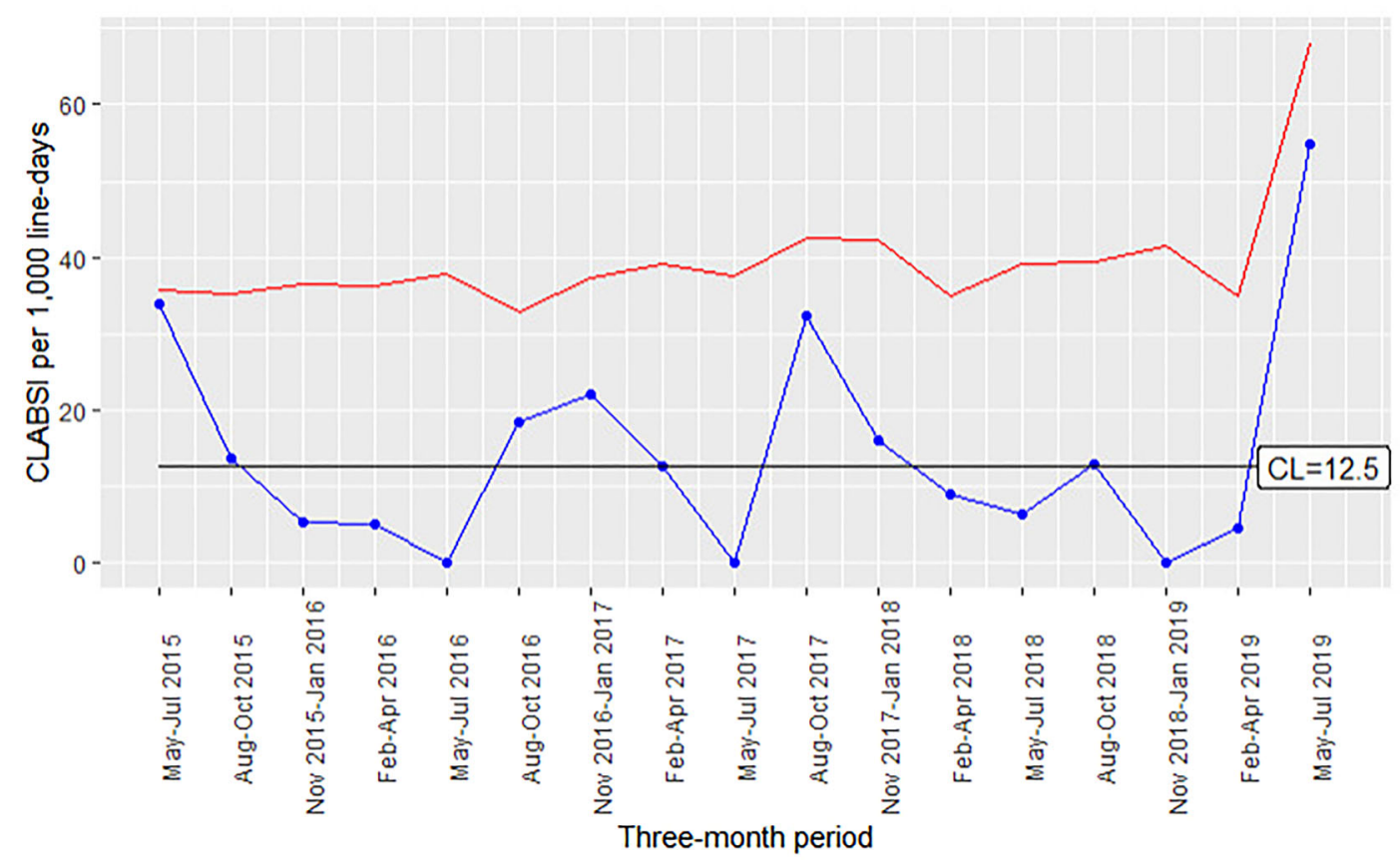

Fig. $3 U$ chart for CLABSI rates by 3 -month periods. The central line $(C L)$ represents the internal mean CLABSI rate from May 15, 2015 to May 15, 2019. The upper line represents the upper control limit (UCL). The lower

incidence of which is unlikely to have been impacted by change in unit configuration. In parallel with the nonsignificant decrease in the number of NI, fewer infants received antibiotic treatment $\geq 72 \mathrm{~h}$ after admission. Nevertheless, LOT and DOT rates remained relatively stable between the two study periods, indicating that single-room care did not impact overall consumption.

\section{Strengths and Limitations}

The strengths of our study include the meticulous data collection and clearly defined NI types. However, our data also have several limitations. First, the limited power of our study may have inherently hindered the results from reaching statistical significance. A repeat analysis with a larger study sample and a longer time series is therefore desirable. Second, we were unable to correct for potential prevailing local temporal trends in NIs due to lack of control limit (LCL) approaches zero and is therefore not depicted. Final quarter (May-Jul 2019) displayed as full 3-month period, although data present up until May 15, 2019

available data. Analysis using segmented interrupted-time series with monthly incidence rates as opposed to a simpler pre- and post-analysis would have allowed for a more refined assessment of the effect of unit transition on infection rates. Lastly, we were unable to identify and model for all other potential modifications in infection-control practices that may have taken place as part of continuous quality improvement efforts.

\section{CONCLUSION}

Based on the data available in this study, the notion that the transition from a historic, openbay ward to a new single-room unit provides added protection against hospital-acquired infections in preterm infants is not supported. Given the complex, multifactorial nature of these infections, improvements primarily lie in whether basic measures such as maintaining adequate staffing levels, limiting the use of 
invasive medical devices, ensuring high level of competency for insertion and maintenance of central-lines, antibiotic stewardship and adherence to hand hygiene, are met. Redesigning a NICU involves substantial budgetary implications and staff adjustment and thus must be based on solid evidence. While our findings thus provide insufficient support for singleroom care as an infection-control strategy, further investigation regarding the influence of NICU room-privatisation on the burden of NIs is therefore warranted, preferably with larger study samples spanning longer time series and a randomised control design.

\section{ACKNOWLEDGEMENTS}

We thank Drs. Erik von Asmuth for his technical advice and assistance on the verification of the $\mathrm{R}$ script for the infection data.

Funding No funding or sponsorship was received for this study or publication of this article.

Authorship All named authors meet the International Committee of Medical Journal Editors (ICMJE) criteria for authorship for this article, take responsibility for the integrity of the work as a whole, and have given their approval for this version to be published.

Authorship Contributions Enrico Lopriore, Jonne M. de Boer, Karin Ellen Veldkamp, Martha T. van der Beek and Vincent Bekker conceived and designed the study; Sophie Jansen, Romy J.M. Berkhout, Alieke van der Hoeven, Barbara Saccoccia and Jonne M. de Boer collected and cleaned the data; Sophie Jansen analysed the data, interpreted the results and wrote the first draft of the manuscript; Enrico Lopriore, Alieke van der Hoeven, Karin Ellen Veldkamp, Martha T. van der Beek and Vincent Bekker interpreted the results; All authors critically revised the manuscript and gave final approval for publication.

Disclosures Sophie Jansen, Enrico Lopriore, Romy Berkhout, Alieke van der Hoeven, Barbara
Saccoccia, Jonne de Boer, Karin Ellen Veldkamp, and Martha van der Beek have nothing to disclose. Vincent Bekker is on the editorial board for Infectious Diseases and Therapy but has nothing else to disclose.

Compliance with Ethics Guidelines Approval and a waiver from the need to provide written informed consent were obtained from the institutional review board of LUMC (G19.070).

Data Availability The datasets generated during and/or analysed during the current study are not publicly available due to the privacy of the participants.

Open Access. This article is licensed under a Creative Commons Attribution-NonCommercial 4.0 International License, which permits any non-commercial use, sharing, adaptation, distribution and reproduction in any medium or format, as long as you give appropriate credit to the original author(s) and the source, provide a link to the Creative Commons licence, and indicate if changes were made. The images or other third party material in this article are included in the article's Creative Commons licence, unless indicated otherwise in a credit line to the material. If material is not included in the article's Creative Commons licence and your intended use is not permitted by statutory regulation or exceeds the permitted use, you will need to obtain permission directly from the copyright holder. To view a copy of this licence, visit http://creativecommons.org/licenses/by$\mathrm{nc} / 4.0 /$.

\section{REFERENCES}

1. Ramasethu J. Prevention and treatment of neonatal nosocomial infections. Matern Heal Neonatol Perinatol. 2017;3:5

2. Stoll BJ, Gordon T, Korones SB, et al. Late-onset sepsis in very low birth weight neonates: a report from the National Institute of Child Health and Human Development Neonatal Research Network. J Pediatr. 1996;129:63-71.

3. Stoll BJ, Hansen N, Fanaroff AA, et al. Late-onset sepsis in very low birth weight neonates; the 
experience of the NICHD Neonatal Research Network. Pediatrics. 2002;110:285-91.

4. Boghossian NS, Page GP, Bell EF, Stoll BJ, Murray JC, Cotton MC, Shankaran S, Walsh MC, Laptook AR, Newman NS, Hale EC, McDondald SA, Das A, Higgins RD. Late-onset sepsis in very low birth weight infants from singleton and multiple gestation births. J Pediatr. 2013;162(6):1120-4.

5. Brodie SB, Sands KE, Gray JE, et al. Occurrence of nosocomial bloodstream infections in six neonatal intensive care units. Pediatr Infect Dis J. 2000;19(1): 56-65.

6. Bannatyne M, Smith J, Panda M, Abdel-Latif ME, Chaudhari T. Retrospective cohort analysis of central line associated bloodstream infection following introduction of a central line bundle in a neonatal intensive care unit. Int J Pediatr. 2018;2018.

7. Bracco D, Dubois MJ, Bouali R, Eggiman P. Single rooms may help to prevent nosocomial bloodstream infection and cross-transmission of methicillin-resistant Staphylococcus aureus in intensive care units. Intensive Care Med. 2007;33:836-40.

8. Stiller A, Salm F, Bischoff P, Gastmeier P. Relationship between hospital ward design and healthcareassociated infection rates: a systematic review and meta-analysis. Antimicrob Resist Infect Control. 2016;5:51.

9. Julian S, et al. Impact of neonatal intensive care bed configuration on rates of late-onset bacterial sepsis and methicillin-resistant Staphylococcus aureus colonization. Infect Control Hosp Epidemiol. 2015;36(10):1173-82.

10. van Veenendaal NR, Heideman WH, Limpens J, van der Lee JH, van Goudoever JB, van Kempen AAMW, van der Schoor SRD. Hospitalising preterm infants in single family rooms versus open bay units: a systematic review and meta-analysis. Lancet Child Adolesc Health. 2019;3(3):147-57.

11. Bizzarro MJ, Ehrenkranz RA, Gallagher PG. Concurrent bloodstream infections in infants with necrotizing enterocolitis. J Pediatr. 2013;164(1):61-6.

12. Bell MJ, Ternberg JL, Feigin RD, Keating JP, Marshall $\mathrm{R}$, Barton L, Brotherton T. Neonatal necrotizing enterocolitis: therapeutic decisions based upon clinical staging. Ann Surg. 1978;187(1):1-7.

13. Benneyan JC. The design, selection, and performance of statistical control charts for healthcare process improvement. Int J Six Sigma Compet Adv. 2008;4(4):209-39.

14. R Core Team (2019). R: A language and environment for statistical computing. R Foundation for
Statistical Computing, Vienna, Austria. https:// www.R-project.org/. Accessed 15 June 2019.

15. Vohr B, McGowan E, McKinley L, Tucker R, Keszler L, Alksninis B. Differential effects of single-family room neonatal intensive care unit on 18- to 24-month Bayley Scores of preterm infants. J Pediatr. 2017;185:42-8.

16. Lester BM, Hawes K, Abar B, Sullivan M, Miller R, Bigsby R, Laptook A, Salisbury A, Taub M, Lagasse LL, Padbury JF. Single-family room care and neurobehavioral and medical outcomes in preterm infants. Pediatrics. 2014;134:754-60.

17. Ortenstrand A, Westrup B, Brostrom EB, Sarman I, Akerstrom S, Brune T, et al. The Stockholm Neonatal Family Centered Care Study: effects on length of stay and infant morbidity. Pediatrics. 2010;125(2):e278-85.

18. Puumala SE, Rich RK, Roy L, Reynolds R, Jimenez FE, Opollo JG, Brittin J. Single-family room neonatal intensive care unit design: do patient outcomes actually change? J Perinatol. 2020;40(6):867-74.

19. Sadowska-Krawczenko I, Jankowska A, Kurylak A. Healthcare-associated infections in a neonatal intensive care unit. Arch Med Sci. 2012;8(5):854-8.

20. Domanico R, Davis DK, Coleman F, Davis BO. Documenting the NICU design dilemma: comparative patient progress in open-ward and singlefamily room units. J Perinatol. 2011;31:281-8.

21. CDC. NHSN Master Organism Common Commensal List. January 2020 (release v9.4).

22. Leistner R, Piening B, Gastmeier P, Geffers C, Schwab F. Nosocomial infections in very low birthweight infants in Germany: current data from the National Surveillance System NEO-KISS. Klin Padiatr. 2013;225:75-80.

23. van der Zwet WC, Kaiser AM, van Elburg RM, Berkhof J, Fetter WPF, Parlevliet GA, VandenbrouckeGrauls CMJE. Nosocomial infections in a Dutch neonatal intensive care unit: surveillance study with definitions for infection specifically adapted for neonates. J Hosp Infect. 2005;61(4):300-11.

24. CDC. Bloodstream infection event (central line-associated bloodstream infection and non-central line associated bloodstream infection). https:// www.cdc.gov/nhsn/pdfs/pscmanual/4psc clabscurrent.pdf. Accessed 16 January 2020.

25. CDC. Pneumonia (Ventilator-associated [VAP] and non-ventilator-associated Pneumonia [PNEU] Event. https://www.cdc.gov/nhsn/PDFs/ pscManual/6pscVAPcurrent.pdf. Accessed 16 January 2020. 
26. AAP: Subcommittee on urinary tract infections, steering committee on quality improvement and management. steering committee on quality improvement and management (2011) Urinary tract infection: clinical practice guideline for the diagnosis and management of the initial UTI in febrile infants and children 2-24 months. Pediatrics. 2011;128(3):595-610.

27. Nederlandse Vereniging van Kindergeneeskunde (NvK). Richtlijn Urineweginfecties bij kinderen. https://werkboeken.nvk.nl/Kwaliteit/Richtlijnenoverzicht/Details/articleType/ArticleView/articleId/ 871. Accessed 16 January 2020.

28. Vergnano S, Buttery J, Cailes B, Chandrasekaran R, Chiappini E, Clark E, Cutland C, de Dourado Andrade S, Esteves-Jaramillo A, Guinazu JR, Jones
C, Kampmann B, King J, Kochhar S, MacDonald N, Mangili A, de Menezes Martins R, Velasco Munoz C, Padula M, Munoz FM, Oleske J, Sanicas M, Schlaudecker E, Spiegel H, Subelj M, Sukumaran L, Tagbo BN, Top KA, Tran D, Heath PT, The Brighton Collaboration Neonatal Infections Working Group. Neonatal infections: case definitions and guidelines for data collection, analysis, and presentation of immunisation safety data. Vaccine. 2016;34: 6038-46.

29. Ku LC, Boggess KA, Cohen-Wolkowiez MC. Bacterial meningitis in the infant. Clin Perinatol. 2015;42(1):29-45.

30. Vermont Oxford Network (VON). 2019 Manual of Operations: Part 2. Data definitions \& infant forms. Release 23.2. February 2019. 